\section{Использование метода конечных элементов для конструкторских расчетов рубительных машин ${ }^{1}$}

\author{
А. Л. Мишичев ${ }^{2}$ \\ Петрозаводский государственный университет
}

\section{АННОТАЦИЯ}

В статье обосновывается использование метода конечных элементов при конструкторских расчетах рубительных машин, описываются его преимущества по сравнению с другими применяемыми методами расчетов.

Ключевые слова: машины рубительные, расчет на прочность, метод конечных элементов.

\section{SUMMARY}

The present article considers some reasons for the use of the final element method in design calculations of chippers, as well as its advantages over other known techniques.

Keywords: chippers, calculation on durability, the final element method.

В настоящее время создание конкурентоспособной высокоэффективной техники приобретает особое значение для отечественных производитетелей оборудования целлюлозно-бумажной промышленности.

Рубительные машины являются основным оборудованием ЦБП, определяющим количественные и качественные показатели работы всего комплекса машин технологического потока.

Процесс получения щепы в рубительных машинах основан на ножевом или резцовом резании древесины в продольно-торцово-поперечном, продольноторцовом, поперчно-торцовом или других по отношению к волокнам направлениях. Режущий инструмент в рубительных машинах размещается на вращающемся рабочем органе - диске, барабане. Их оснащают устройствами для подачи и загрузки сырья, средствами для эвакуации из рабочего объема рубительных машин готовой щепы, а также средствами для транспортирования ее в сборную емкость. По конструктивным схемам механизма резания (режущего органа) рубительные машины можно разделить на три основных класса: дисковые, барабанные и конические. Увеличение производительности рубительных машин осуществляется за счет увеличения количества режущих ножей диска и увеличения частоты его вращения

\footnotetext{
${ }^{1}$ Работа выполнена под руководством д.т.н., профессора, академика РАЕН А. В. Питухина, д.т.н., профессора С. Б. Васильева

2 Автор - аспирант кафедры технологии металлов и ремонта

(C) А. Л. Мишичев, 2003
}

при улучшении или сохранении качества вырабатываемой щепы [1]. Такие тенденции требуют совершенствования функций всех частей машины, увеличения надежности ее работы. Важную роль при этом играет усовершенствование процесса ее проектирования.

На сегодняшний день при проектировании элементов конструкций рубительных машин по существующим методикам [1-3] рассчитываются на прочность следующие основные детали машины: вал рубительной машины, подшипники вала, ножевой диск и его крепление к валу, крепления режущих ножей, крепления лопаток к ободу диска. Расчеты на прочность деталей машины производятся при наиболее тяжелых условиях работы, т.е. при рубке бревен максимально возможного диаметра и с учетом колебательных процессов в отдельных деталях машины.

Вал рубительной машины рассчитывают на прочность, жесткость, поперечные и крутильные колебания. Проектный, или предварительный, расчет вала на прочность производится по деформациям изгиба и кручения. При этом расчете определяют размеры сечений отдельных участков вала. Длину участка вала выбирают из конструктивных соображений с учетом наиболее компактного расположения деталей. После конструктивного оформления вала машины производят проверочный расчет, при котором определяют коэффициенты запаса прочности в опасных сечениях.

Расчет (выбор) подшипников качения для опоры вала рубительной машины производят по методу динамически нагруженных подшипников. При полученных расчетом на прочность диаметрах участков вала подшипники рассчитывают по коэффициенту работоспособности.

Конструктивные размеры диска назначают из условий размещения ножей и создания потребного махового момента. При расчете на прочность материала диска выполняют лишь проверочный расчет для определения действительных напряжений и коэффициентов запаса прочности. Расчет болтов крепления ножевого диска к валу, крепления режущих ножей и крепления лопаток к ободу диска производят исходя из деформации среза и растяжения.

При анализе применяемых методов расчета элементов конструкции рубительных машин можно сделать вывод, что эти расчеты, основанные на коэффициентах запаса прочности, не позволяют эффективно использовать методы оптимального проектирования, учитывать качество изготовления деталей, эффективно внедрять САПР. Классический подход в механике материалов не раскрывает самого механизма разрушения, который с достаточной точностью может быть представлен с позиции механики разрушения. 
Поэтому при изготовлении основных элементов рубительных машин необходимо использовать уточненный метод расчета на прочность - метод конечных элементов (МКЭ) [4]. Кроме этого, применение МКЭ при расчете элементов рубительных машин обусловлено тем, что решения о допуске в эксплуатацию или ремонте изделий с дефектами принимаются не на основании уточненных методов расчета на прочность с использованием принципов механики разрушения и МКЭ, а из опыта эксплуатации или в соответствии с технической документацией, что приводит к неоправданному завышению объема ремонтных работ.

Нагляднее всего преимущество МКЭ можно представить при расчете диска рубительной машины. Ножевой диск (рис.1) - основной рабочий орган рубительной машины, от эффективности его работы зависит не только производительность рубительной машины, но и качество получаемой технологической щепы. Диск имеет наклонные (по ходу) относительно радиуса сквозные окна для выхода щепы. В гнезда окон вставляют режущие ножи, которые располагают на специальных опорах, установленных на теле диска. Прижим ножей обеспечивается с помощью болтов. Таким образом, диск служит как опора для ножей и для передачи усилия на ножи от электродвигателя, поэтому на условия работы диска влияет удельная сила резания. Удельная сила резания зависит от толщины срезаемого слоя, геометрических параметров резания и свойств древесины. При изготовлении щепы толщина задается выпуском ножей над поверхностью диска, а длина определяется расстоянием между соседними лезвиями ножей неподвижного ножевого набора. Геометрические параметры резания определяются типом и размерами используемых ножей. Сложность определения удельной силы резания заключается в том, что нельзя спрогнозировать влияние на нее физико-механических свойств древесины (порода, состояние, время года).

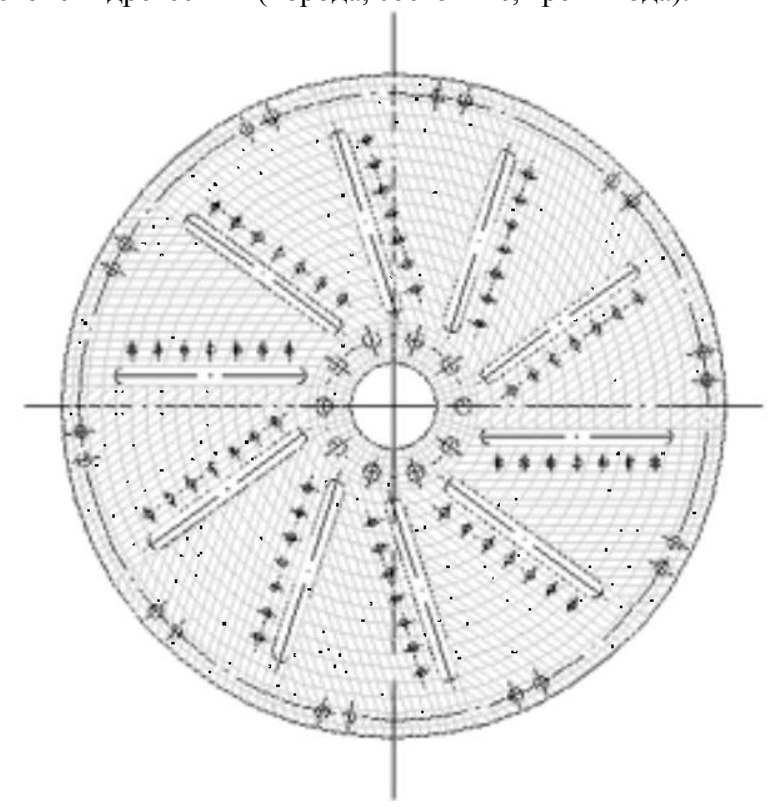

Рис. 1. Ножевой диск рубительной машины МРН-100
Для учета этих свойств при расчете удельной силы резания используются различные коэффициенты, что не отражает действительного значения удельной силы резания, а следовательно, и не позволяет достаточно точно рассчитать нагрузку на ножевой диск. Поэтому здесь необходимо применять методы расчета на прочность с использованием принципов механики разрушения и МКЭ. При расчете диска рубительной машины с использованием МКЭ также учитываются такие конструктивные элементы, как отверстия для крепления диска на валу, для крепления режущих ножей и крепления лопаток к ободу диска, сквозные пазы для размещения ножей. При этом проведение расчета методом конечных элементов будет состоять из следующих этапов [5]:

1. Разбиение тела на конечные элементы и назначение узлов, в которых определяются перемещения.

2. Определение зависимостей между усилиями и перемещениями в узлах элемента, т.е. построение матрицы жесткости.

3. Составление системы алгебраических уравнений равновесия (сборка).

4. Решение системы уравнений.

5. Определение компонентов напряженнодеформированного состояния тела.

Применение математического аппарата МКЭ упрощает построение модели объекта, состоящего из набора конечных элементов. МКЭ позволяет получать решение в виде полей напряжений и деформаций практически в любом сечении элемента. Эти преимущества метода до настоящего времени еще не были использованы при конструировании дисковых рубительных машин. Их реализация может снизить металлоемкость оборудования, увеличить надежность его работы и снизить себестоимость и, в конечном итоге, повысить качество вырабатываемой щепы.

\section{СПИСОК ЛИТЕРАТУРЫ}

1. Вальщиков Н. М. Рубительные машины. Л.: Машиностроение, 1970. 328 с.

2. Рушнов Н. П. Рубительные машины. М.: Лесн. пром-ть, 1985. $208 \mathrm{c.}$

3. Гомонай М. В. Многорезцовые рубительные машины. М.: Лесн. пром-ть, 1990. 144 с.

4. Зенкевич О. Метод конечных элементов в технике. М.: Мир, 1975. 539 с.

5. Морозов Е. М. Метод конечных элементов в механике разрушения. М.: Наука, 1980. 256 с. 